\title{
A CONSTRUÇÃO DE UNIDADE TEMÁTICA SOBRE POLUIÇÃO ATMOSFÉRICA BASEADA EM METODOLOGIAS ATIVAS PARA O ENSINO MÉDIO
}

Gislaine Penha Rossetto José Ribeiro Gregório Daniele Trajano Raupp

\section{Introdução}

Neste trabalho objetivamos apresentar a construção de uma unidade temática sobre poluição atmosférica como contribuição para o processo de ensino e aprendizagem em Química, bem como colaborar para a formação de indivíduos mais reflexivos quanto às questões ambientais. Este trabalho foi produzido através do PROFQUI Mestrado Profissional em Química em Rede Nacional no Polo Regional da Universidade Federal do Rio Grande do Sul - UFRGS e pertence à linha de pesquisa LP2- Química Ambiental e energia.

Devido aos graves e preocupantes problemas ambientais enfrentados pela sociedade atual, torna-se imprescindível a discussão da temática ambiental nas escolas, para que o educando desenvolva valores e atitudes 
que preservem o meio ambiente, possibilitando uma mudança do cenário ambiental do nosso planeta. Ademais, a abordagem da temática em sala de aula engloba diversos conceitos químicos e abre grandes possibilidades de reflexões, discussões e aprendizagens. No contexto da escola, a Educação Ambiental - EA, a partir do estudo das relações do homem com a natureza, colabora para que o aluno desenvolva um posicionamento reflexivo sobre o meio que o cerca.

Trazer temas sociais para a sala de aula faz com que os alunos tenham condições de se posicionarem criticamente, desenvolvendo o senso crítico da necessidade de conservação e a preservação do meio ambiente. Estudar química ambiental não só permite que o aluno compreenda os fenômenos naturais, mas também o ajuda a compreender o complexo mundo social que ele vive. De acordo com Ressetti:

Acreditamos que a utilização de temas geradores ambientais nas aulas de Química, sob esta abordagem, constitui um importante processo para se trabalhar a conscientização juntamente com a apropriação dos conteúdos químico-científicos, dando condições para que os educandos possam interpretar de forma crítica a realidade em que vivem, articulando o conhecimento químico às questões sociais, ambientais, econômicas e políticas (RESSETTI, 2007, p.1). 
Diante da relevância de se trabalhar temas ambientais em sala de aula, este trabalho se propõe a apresentar uma unidade temática de química ambiental, com foco na poluição atmosférica e sua relação direta com os conteúdos de química, viabilizando dar ao aluno uma motivação maior para a aprendizagem. Além de estabelecer intrínseca relação entre conteúdo químico e contexto do aluno, as atividades propostas podem ser realizadas com materiais de fácil disponibilidade e com foco em estratégias pedagógicas para promoção do aprendizado na qual o aluno é agente ativo e participativo.

Dessa forma, para a operacionalização das atividades se utilizou estratégias em que o aluno é estimulado a assumir uma postura ativa no processo de aprendizagem, o que rompe com o modelo tradicional de ensino, no qual o aluno apenas "assiste" à aula e busca absorver algum conhecimento que está sendo transmitido naquele momento. A nova Base Nacional Comum Curricular BNCC propõe a superação do ensino tradicional, e orienta que o ensino não deve ser fragmentado e descontextualizado, mas que o aluno precisa ser estimulado a aplicar os conteúdos na vida real, dando sentido ao que aprendeu. Dessa forma, o aluno não deve ser tratado como espectador, e sim como protagonista (BRASIL, 2017). Desenvolver novas estratégias educacionais em que o aluno é protagonista resulta numa mudança da prática pedagógica, ou seja, numa inovação. Como afirmam Camargo e Daros (2018): 
Criar condições de ter uma participação mais ativa dos alunos implica, absolutamente, a mudança da prática e o desenvolvimento de estratégias que garantam a organização de um aprendizado mais interativo e intimamente ligado com as situações reais. Por isso, a inovação na educação é essencialmente necessária. A inovação é uma das formas de transformar a educação (CAMARGO; DAROS, 2018, p.4).

Quando os sujeitos que estão presentes na sala de aula compreendem que é através das relações que se aprende, e que o professor não é o único responsável pela efetiva aprendizagem, todos contribuem para um objetivo comum, aprender. Com isso, ressalta-se que a postura do professor em sala de aula pode facilitar ou não a aprendizagem. Se o professor assumir uma posição de ser aprendente, ou seja, que está constantemente aprendendo e não somente ensinando, o ambiente em sala será de cooperação. Com isso, o aluno percebe que sua participação é essencial e que suas colocações, dúvidas e conhecimentos contribuem para a construção da sua própria aprendizagem, bem como a todos da sala de aula.

As estratégias pedagógicas utilizadas nesta unidade visam superar a educação bancária criticada por Paulo Freire e (1987), em que o professor transmite o conhecimento para o aluno e depois, para ser aprovado, o aluno precisa devolver exatamente o conhecimento que 
recebeu, assim como em uma transação bancária. Dessa maneira, o professor não estimula a análise crítica, e sim a memorização dos conteúdos.

Pesquisas têm mostrado que o ensino de Química geralmente vem sendo estruturado em torno de atividades que levam à memorização de informações, fórmulas e conhecimentos, que limitam o aprendizado dos alunos e contribuem para a desmotivação em aprender e estudar Química (SANTOS et al., 2013, p.1). Percebe-se assim que é necessário mais do que conteúdos disciplinares, já que na sociedade atual é fundamental o estudante aprender a aprender, e desenvolver diversas competências. "A sala de aula precisa ser ativa e significativa ao proporcionar espaços de construção de conhecimento" (RAUPP et al., 2019, p.16). Ainda, segundo as diretrizes da BNCC, para que o aluno desenvolva competências necessárias para a vida em sociedade, é preciso muito mais do que acumular informações que são repassadas na escola.

No novo cenário mundial, reconhecer-se em seu contexto histórico e cultural, comunicar-se, ser criativo, analítico-crítico, participativo, aberto ao novo, colaborativo, resiliente, produtivo e responsável requer muito mais do que o acúmulo de informações. Requer o desenvolvimento de competências para aprender a aprender, saber lidar com a informação cada vez mais disponível, atuar com discernimento e responsabilidade nos contextos das culturas digitais, aplicar conhecimentos para resolver pro- 
blemas, ter autonomia para tomar decisões, ser proativo para identificar os dados de uma situação e buscar soluções, conviver e aprender com as diferenças e as diversidades (BRASIL, 2017, p.14).

Nesse sentido, as metodologias ativas de ensinoaprendizagem possuem um importante papel, pois têm como principal característica a inserção do estudante como agente principal e responsável pela construção da sua aprendizagem. Na BNCC é colocado que o aluno precisa ser o protagonista no processo de ensino e aprendizagem, pois dessa forma, o aluno aprende a ter criatividade, autonomia, pensamento crítico e outros valores essenciais para a formação de cidadãos ativos na sociedade. Além disso, ao desenvolver a autonomia, o aluno aprende a refletir antes de tomar as próprias decisões sobre os benefícios e malefícios, e aprende a assumir responsavelmente as consequências de suas escolhas. Com isso, os alunos desenvolvem habilidades para lidar consigo e com a sociedade em que está inserido.

[...] que garanta aos estudantes ser protagonistas de seu próprio processo de escolarização, reconhecendo-os como interlocutores legítimos sobre currículo, ensino e aprendizagem. Significa, nesse sentido, assegurar--lhes uma formação que, em sintonia com seus percursos e histórias, permita-lhes definir seu projeto de vida, tanto no que diz respeito ao estudo e ao trabalho como também no que concerne às escolhas 
de estilos de vida saudáveis, sustentáveis e éticos (BRASIL, 2017, p.463).

Embora as metodologias ativas estejam em destaque nas últimas décadas, segundo Costa e Coutinho (2019), seus aspectos remontam ao fim do século XIX. Podendo citar como exemplo John Dewey (1979), que dava ênfase ao "aprender a aprender", propondo o modelo de ensino-aprendizagem focado no aluno e a partir da problematização dos conhecimentos prévios dos mesmos alunos (PEREIRA et al., 2009). Anteriormente Edouard Claparède (CLAPARÈDE, 1920, apud MAULINI, 1996), tratou de temas como a afetividade e suas relações com o interesse e a inteligência. De uma forma geral, as metodologias ativas podem ser compreendidas como práticas pedagógicas motivadoras. No âmbito da renovação metodológica, as metodologias ativas "são metodologias de ensino que envolvem os alunos em atividades diferenciadas, com vários aspectos e maneiras de ensino, a fim de desenvolver habilidades diversificadas" (SANTOS; NETO; FRAGOSO, 2018, p.531). Atualmente, entende-se que as metodologias de ensino são tão importantes quanto os próprios conteúdos abordados em sala de aula (PAIVA et al., 2016).

As possibilidades para desenvolver metodologias ativas em sala de aula são inúmeras. Podendo se optar por uma metodologia ativa específica, como a da aprendizagem baseada em problemas (problem-basedlearning PBL), a aprendizagem baseada em equipe (team- 
basedlearning - TBL), estudo de casos, sala de aula invertida (flippedclassroom), instrução pelos pares ou colegas (peerinstruction), ensino sob medida (just in time teaching), entre outros (DE MIRANDA MORAES; CARVALHO; NEVES, 2016; PAIVA et al., 2016).

Assim, o diferencial do produto educacional construído nesse trabalho é a metodologia utilizada, pois as atividades sugeridas foram desenvolvidas de modo a privilegiar o estudante como agente principal responsável pela sua aprendizagem. Além disso, a contextualização realizada com o uso da temática poluição atmosférica tem como fundamento a Teoria da Aprendizagem Significativa de Ausubel, que possibilita ampliar a visão de como o indivíduo constrói seu conhecimento e a relevância do conhecimento prévio do aluno para esse processo. Dessa forma espera-se que, ao utilizar uma abordagem contextualizada, baseada em conhecimentos prévios e utilizando metodologias ativas, o aluno possa interagir ativamente, trazendo seu cotidiano para a sala de aula. Essa abordagem objetiva tornar as questões científicas relevantes, fazendo a ponte entre o conhecimento conceitual e as situações da vida real.

\section{Desenvolvimento}

A Unidade temática com o tema "Poluição atmosférica: um inimigo invisível” foi desenvolvida para profes- 
sores que buscam algo mais profundo do que simplesmente ensinar conteúdos isolados e sem um significado real para o aluno. A unidade temática é proposta em oito etapas (cada uma podendo ser trabalhada em $2 \mathrm{~h}$-aula, mas também o professor pode optar por adaptar de acordo com sua realidade e necessidade). Recomendada para alunos do $1^{\circ}$ ano do Ensino Médio, sugere-se que a temática seja relacionada com conteúdos químicos já abordados em sala de aula tais como os estados físicos da matéria, propriedades físicas da matéria, interações intermoleculares, reações de neutralização e gases. Porém, a ênfase é dada ao conteúdo de compostos inorgânicos.

Para a construção da unidade temática, as estratégias de ensino foram elaboradas para que o aluno passe da posição passiva e receptora para uma posição ativa e construtora do seu próprio conhecimento. O livro "A sala de aula inovadora: estratégias pedagógicas para fomentar o aprendizado ativo", de Fausto Camargo e Thuinie Daros (2018), foi utilizado como inspiração para o planejamento das estratégias pedagógicas aplicadas nessa unidade. Por meio desse livro buscou-se compreender como é possível renovar a prática pedagógica por meio de mudanças nas metodologias e utilizando novas estratégias de ensino.

A estrutura da unidade temática é constituída por introdução, a qual expõe para o professor a relevância do tema e da metodologia utilizada. Logo após, as oito eta- 
pas são descritas, especificando os objetivos que se pretende alcançar, os recursos didáticos necessários, um cronograma com as atividades que serão desenvolvidas na etapa e um detalhamento dessas atividades. Em algumas etapas, de acordo com a necessidade, é apresentado um aprofundamento químico teórico da temática que será trabalhada na etapa. Além disso, no decorrer das atividades, são sugeridos materiais de apoio, os quais são disponibilizados no final da unidade temática ou, se o professor optar, pode acessar o repositório digital criado com todos os materiais da unidade temática "Poluição atmosférica: um inimigo invisível"1. Para compreender melhor a organização da Unidade Temática, foi elaborado um panorama geral através do quadro 1 . A cada etapa, tem-se uma sequência de atividades diferenciada, de acordo com os objetivos propostos para aquele momento.

Quadro 1: Resumo das atividades desenvolvidas na unidade temática.

\begin{tabular}{|l|l|l|}
\hline Aula & \multicolumn{1}{|c|}{ Objetivo da aula } & \multicolumn{1}{|c|}{ Atividades } \\
\hline 1 & - Conhecer a concepção prévia & - Questionário inicial; \\
& dos alunos com relação a temas & - Apresentação do ví- \\
& ambientais que serão trabalha- & deo; \\
& dos no decorrer da unidade; & - Problematização inici- \\
& -Perceber a importância da at- & al; \\
& mosfera para a manutenção da & - Atividades experimen- \\
& vida na terra; & tais com uma aborda- \\
& - Conhecer a divisão da atmosfe- \\
& gem POE (predizer, \\
& gcões químicas; & \\
\hline
\end{tabular}

${ }^{1}$ Link para o repositório https://bit.ly/33F3gZX 


\begin{tabular}{|c|c|c|}
\hline & $\begin{array}{l}\text { - Compreender a organização } \\
\text { das moléculas nos diferentes } \\
\text { estados físicos, e as interações } \\
\text { intermoleculares; } \\
\text { - Compreender os conceitos de } \\
\text { propriedades físicas da matéria } \\
\text { aplicados à temática atmosfera; } \\
\text { - Aplicar algumas propriedades } \\
\text { dos gases à temática atmosfera. }\end{array}$ & \\
\hline 2 & $\begin{array}{l}\text { Perceber a poluição atmosférica } \\
\text { como um problema ambiental; } \\
\text { Proporcionar aos alunos momentos } \\
\text { de discussões sobre poluição a } \\
\text { partir de reportagens; } \\
\text { Compreender o problema poluição } \\
\text { e identificar suas causas e conse- } \\
\text { quências. }\end{array}$ & $\begin{array}{l}\text { - Construção de um } \\
\text { mural de fatos e notí- } \\
\text { cias com a temática } \\
\text { poluição; } \\
\text { - Construção de uma } \\
\text { árvore de problemas } \\
\text { com a temática polui- } \\
\text { ção; } \\
\text { - Debate sobre a cons- } \\
\text { trução do mural de fatos } \\
\text { e notícias e árvore de } \\
\text { problemas. }\end{array}$ \\
\hline 3 & $\begin{array}{l}\text { - Perceber a poluição atmosférica } \\
\text { como um problema ambiental; } \\
\text { Compreender como a ação do } \\
\text { homem contribui para problemas } \\
\text { ambientais; } \\
\text { Valorizar atitudes que contribuem } \\
\text { para a preservação do meio ambi- } \\
\text { ente, principalmente a qualidade } \\
\text { do ar. }\end{array}$ & $\begin{array}{l}\text { - Aula expositiva e } \\
\text { dialogada com auxílio } \\
\text { de slides. }\end{array}$ \\
\hline 4 & $\begin{array}{l}\text { - Construir um mapa conceitual } \\
\text { de forma que contribua para a } \\
\text { aprendizagem; } \\
\text { - Sintetizar e organizar os concei- } \\
\text { tos e informações discutidos nas } \\
\text { aulas anteriores; } \\
\text { - Desenvolver capacidade argu- }\end{array}$ & $\begin{array}{l}\text { - Construção pelo pro- } \\
\text { fessor de um mapa } \\
\text { conceitual; } \\
\text { - Construção pelos } \\
\text { alunos em coletivo de } \\
\text { um mapa conceitual; } \\
\text {-Como trabalho avaliati- }\end{array}$ \\
\hline
\end{tabular}




\begin{tabular}{|c|c|c|}
\hline & mentativa; & $\begin{array}{l}\text { vo, sugere-se que os } \\
\text { alunos, posteriormente, } \\
\text { construam um texto } \\
\text { dissertativo sintetizando } \\
\text { as ideias colocadas no } \\
\text { mapa conceitual. }\end{array}$ \\
\hline 5 & $\begin{array}{l}\text { - Compreender a formação da } \\
\text { chuva ácida; } \\
\text { - Ampliar e aplicar os conhecimen- } \\
\text { tos sobre compostos inorgânicos } \\
\text { no tema chuva ácida; } \\
\text { - Identificar as causas e conse- } \\
\text { quências da chuva ácida para o } \\
\text { ambiente; } \\
\text { - Reconhecer a relação chuva } \\
\text { ácida e poluição atmosférica; } \\
\text {-Conhecer o funcionamento e } \\
\text { importância do conversor catalítico } \\
\text { nos escapamentos dos veículos; } \\
\text {-Compreender os conceitos quími- } \\
\text { cos envolvidos no conversor cata- } \\
\text { lítico. }\end{array}$ & $\begin{array}{l}\text { - Explicação chuva } \\
\text { ácida e sua relação } \\
\text { com a poluição; } \\
\text { - Utilização do recur- } \\
\text { so LabVirt; } \\
\text { - Atividade e discussão } \\
\text { sobre "Como combinar } \\
\text { desenvolvimento eco- } \\
\text { nômico e preservação } \\
\text { ambiental?" } \\
\text { - Preparação para a } \\
\text { visitação da próxima } \\
\text { aula. }\end{array}$ \\
\hline 6 & $\begin{array}{l}\text { - Vivenciar as discussões realiza- } \\
\text { das em sala de aula sobre polui- } \\
\text { ção; } \\
\text { - Ampliar os conhecimentos sobre } \\
\text { desenvolvimento econômico e } \\
\text { preservação ambiental; } \\
\text { - Estimular a reflexão sobre cidada- } \\
\text { nia; } \\
\text { - Estimular o senso crítico. }\end{array}$ & $\begin{array}{l}\text { - Compartilhar os ques- } \\
\text { tionamentos feitos na } \\
\text { aula anterior sobre a } \\
\text { empresa que será reali- } \\
\text { zada a visita; } \\
\text { - Discutir e ampliar } \\
\text { esses questionamentos } \\
\text { com contribuições dos } \\
\text { demais colegas; } \\
\text { - Visita à empresa; } \\
\text { - Retorno à escola e } \\
\text { discussão sobre a visi- } \\
\text { ta. }\end{array}$ \\
\hline 7 & $\begin{array}{l}\text { - Desenvolver habilidades cogniti- } \\
\text { vas como alfabetização visual, }\end{array}$ & $\begin{array}{l}\text { - Construção } \\
\text { um infográfico. }\end{array}$ \\
\hline
\end{tabular}




\begin{tabular}{|c|c|c|}
\hline & $\begin{array}{l}\text { interpretação de imagens e sínte- } \\
\text { se de informações; } \\
\text { - Criar um infográfico como meio } \\
\text { de veicular informação para a } \\
\text { comunidade escolar; } \\
\text { - Proporcionar momentos de refle- } \\
\text { xão sobre a responsabilidade que } \\
\text { temos de cuidar e preservar o } \\
\text { meio ambiente; } \\
\text { - Valorizar atitudes que contribuem } \\
\text { para a preservação do meio ambi- } \\
\text { ente, principalmente a qualidade } \\
\text { do ar. }\end{array}$ & \\
\hline 8 & $\begin{array}{l}\text { - Integralizar as informações colo- } \\
\text { cadas nos infográficos construído } \\
\text { pelos grupos; } \\
\text { - Verificar as aprendizagens cons- } \\
\text { truídas durante a aplicação da } \\
\text { Unidade Temática. }\end{array}$ & $\begin{array}{l}\text { - Apresentação e expli- } \\
\text { cação do infográfico } \\
\text { para o restante da tur- } \\
\text { ma; } \\
\text { - Encerramento da } \\
\text { unidade temática; } \\
\text { - Questionário com } \\
\text { questões abertas e } \\
\text { questões tipo esca- } \\
\text { la Likert. }\end{array}$ \\
\hline
\end{tabular}

Fonte: Os autores

Para a etapa um, os recursos didáticos necessários são data show, computador e laboratório de ciências, ou sala de aula com espaço amplo. Como atividade inicial, o professor pode aplicar um questionário com o objetivo de verificar os conhecimentos que os alunos possuem sobre a temática da unidade. De acordo com Moreira e Masini (1982), a teoria de Ausubel afirma que a aprendizagem só será significativa se o novo conhecimento for ancorado às estruturas cognitivas já existentes no aluno, ou 
seja, seu conhecimento prévio. Com isso, para que o professor faça a mediação, é preciso conhecer e compreender a realidade e o conhecimento dos alunos. Compreendendo a importância do conhecimento prévio para a aprendizagem significativa, o questionário aplicado inicialmente tem como objetivo conhecer, para delimitar e traçar os futuros passos que serão dados no processo de ensinoaprendizagem.

Assim, a aprendizagem significativa ocorre quando novos conceitos, ideias, proposições interagem com outros conhecimentos relevantes e inclusivos, claros e disponíveis na estrutura cognitiva, sendo por eles assimilados, contribuindo para sua diferenciação, elaboração e estabilidade (MOREIRA; 2008, p.24).

Posteriormente, a sugestão é de apresentar para os alunos a unidade e mostrar o tema e as atividades que serão desenvolvidas nas próximas aulas. Após a apresentação da unidade, para iniciar e fomentar a discussão, bem como despertar a curiosidade e motivação dos alunos com relação ao tema, assistir um vídeo com os alu$\operatorname{nos}^{2}$. Nesse vídeo são demonstradas, de forma didática, ilustrativa e com situações do cotidiano, as consequências da poluição atmosférica para o ambiente.

${ }^{2}$ https://www.youtube.com/watch?v=ALDzZc53bkM\&t=131s 
O professor pode solicitar aos alunos que durante a execução do vídeo anotem os principais pontos e o que eles identificaram como interessante e novo. Logo após, pode-se discutir sobre as anotações, demonstrando interesse, ou seja, valorizando os posicionamentos feitos. Como recomenda Morán "não é satisfatório didaticamente exibir o vídeo sem discuti-lo, sem integrá-lo com o assunto de aula, sem voltar e mostrar alguns momentos mais importantes" (MORÁN, 1995, p.30). Nesse momento, é imprescindível prestar atenção nas colocações dos alunos, para que durante o desenvolvimento da unidade, o professor consiga focar e trabalhar, a partir das dúvidas, curiosidades e equívocos levantados nessa primeira etapa, tanto através do questionário como na discussão sobre o vídeo.

Esse momento tem a pretensão de ser um organizador prévio, recomendado por Ausubel, propiciando uma interação entre conceitos novos com os já existentes, buscando, dessa forma, uma aprendizagem significativa. Os organizadores prévios são atividades introdutórias, que facilitam a aprendizagem de novos conceitos. Segundo Moreira (2008) alguns exemplos de organizadores prévios são: textos, dramatizações, filmes, discussão. Além disso, o autor explica para que servem os organizadores prévios.

Os organizadores prévios podem tanto fornecer "ideias âncora" relevantes para a 
aprendizagem significativa do novo material, quanto estabelecer relações entre ideias, proposições e conceitos já existentes na estrutura cognitiva e aqueles contidos no material de aprendizagem, ou seja, para explicitar a relacionabilidade entre os novos conhecimentos e aqueles que o aprendiz já tem, mas não percebe que são relacionáveis aos novos (MOREIRA, 2008, p.24).

A seguir, em uma aula expositiva e dialogada, a sugestão é trabalhar o tema atmosfera. O professor pode iniciar esse momento através de questionamentos, como por exemplo: O que é atmosfera terrestre? Não sinto nada sobre minha cabeça, então, será que ela realmente existe?Para intensificar esse momento, outra sugestão é colocar as palavras "atmosfera terrestre" no centro do quadro de giz, e escrever ao redor as colocações dos alunos sobre os questionamentos citados acima.

Após essa discussão inicial, o professor pode expor os conteúdos aos alunos: composição química da atmosfera, importância da atmosfera e propriedade dos gases. Para isso, o professor pode utilizar o quadro-negro ou slides com imagens e animações de forma atrativa e cativante. Ressalta-se que na unidade temática são disponibilizadas sugestões de slides e um texto com o aprofundamento químico teórico sobre a temática atmosfera. De acordo com a carga horária da disciplina o professor pode trabalhar mais detalhadamente os conceitos de pressão, densidade, organização das moléculas nos dife- 
rentes estados físicos, interações intermoleculares e propriedades dos gases com a temática atmosfera, através de experimentos. Dessa forma, as atividades experimentais têm como objetivo a intensificação da aprendizagem através das discussões e reflexões das hipóteses, observações, coleta e análise de dados dos experimentos.

O primeiro experimento proposto trata sobre a diferença na espessura da troposfera nos polos e na região do Equador. Para ilustrar esse fenômeno em sala de aula, o professor pode trabalhar com o experimento "Balão que murcha e enche sozinho" (figura 1), no qual se prende uma bexiga no gargalo de uma garrafa e logo após mergulha-se a garrafa num recipiente com água fria (o balão ficará murcho) e depois com água quente (o balão ficará inflado).

Figura 1: Experimento "Balão que enche e murcha sozinho".
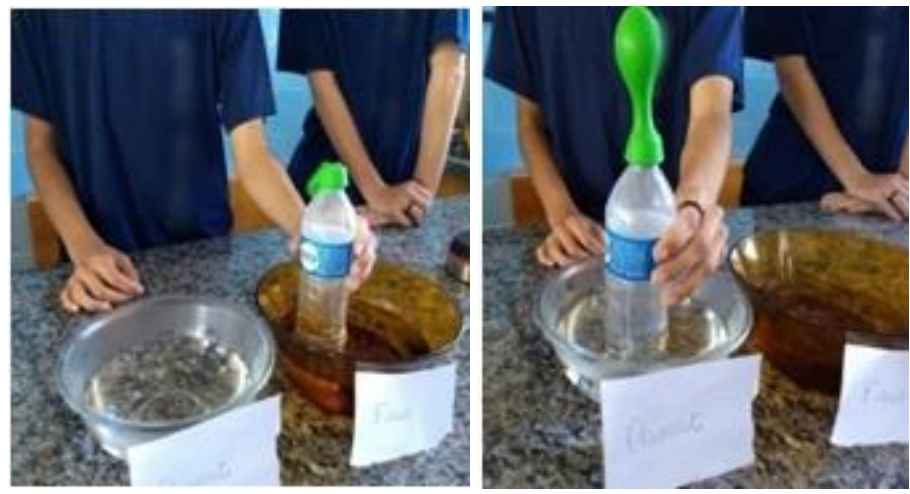

Fonte: Os autores 
O segundo experimento proposto trata sobre a influência da pressão atmosférica, demonstrando na prática a sua existência. O nome do experimento é "Garrafa que engole o ovo" (figura 2), no qual é colocado um algodão em chamas no interior de uma garrafa de vidro e, logo após, um ovo cozido no gargalo da garrafa. Quando o ovo é colocado no gargalo da garrafa e a combustão do algodão cessa, o ovo é empurrado pela ação da pressão atmosférica para dentro da garrafa.

Figura 2: Experimento "Garrafa que engole ovo".

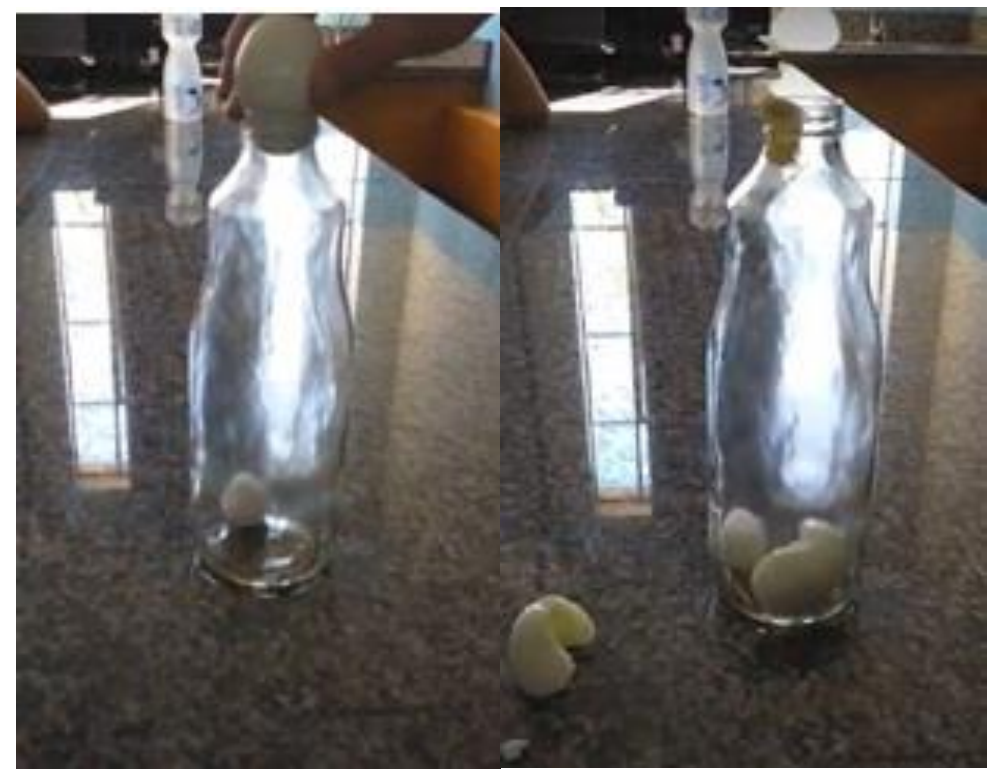

Fonte: Os autores

Para acentuar as discussões através dos experimentos, o professor pode utilizar a abordagem POE (Pre- 
dizer, Observar e Explicar). Essa estratégia é constituída por três etapas: o predizer, onde os alunos, antes da realização do experimento, predizem o resultado esperado (SCHWAHN; OIAGEN, 2008). Em seguida, os estudantes devem observar o que aconteceu no experimento. $\mathrm{E}$ a última etapa dessa estratégia é o explicar, momento em que o aluno deve propor uma explicação do fenômeno, retomando as predições feitas no início do experimento (OLIVEIRA, 2003).

Desta forma, pode-se perceber a participação ativa do aluno no levantamento de hipóteses, na realização do experimento, na coleta e na análise de dados. A realização da atividade experimental, não busca somente a comprovação dos conceitos trabalhados em aula, mas sim contribuir para a crítica e reflexão dos alunos quanto às ideias contidas no experimento e, além disso, o desenvolvimento de habilidades cognitivas que auxiliarão o aluno a resolver problemas e perceber o mundo de uma forma que lhe faça sentido. Dessa forma, para que a experimentação tenha significado no processo de aprendizagem, é preciso que aluno seja ativo e reflexivo (SUART, 2008).

Para a etapa dois, os alunos terão a oportunidade de conhecer o problema da poluição e perceber o quanto ela faz parte do cotidiano das pessoas. Os recursos didáticos necessários para a segunda etapa são post-its e notícias relacionadas à poluição, as quais podem ser solicitadas aos alunos numa aula anterior, ou nos apêndices da 
unidade temática serem disponibilizadas algumas reportagens. Para isso, a sugestão é iniciar a aula com a estratégia "Mural de fatos e notícias". Essa atividade "permite aos alunos discutirem assuntos relacionados com determinado tema, notícia ou fato real" (CAMARGO; DAROS, 2018, p.83), proporcionando uma visão maior sobre o tema e formando conceitos e ideias que serão aprofundadas nas atividades posteriores.

Inicialmente a turma é dividida em grupos de no mínimo três e no máximo cinco alunos, para que debatam e exponham as anotações feitas em casa. Durante esse momento, é importante que o professor circule pela sala, incentivando as discussões e atuando como um mediador, estabelecendo ligações entre o conteúdo teórico e os problemas ilustrados nas notícias. Os alunos podem elaborar ou extrair problemas ou questionamentos a serem pesquisados posteriormente. Podem também estabelecer relações entre as reportagens, até mesmo relações divergentes. Para o fechamento dessa atividade, o professor pode solicitar que os estudantes utilizem sua criatividade e construam um mural de fatos e notícias sobre o tema poluição. A Figura 3 ilustra um exemplo de mural construído pelos alunos. Para isso, eles podem utilizar uma cartolina, folha de flip-chart ou um espaço na parede da sala. 
Figura 3: Representação de fragmento do mural de fatos e notícias construído por um grupo de alunos.

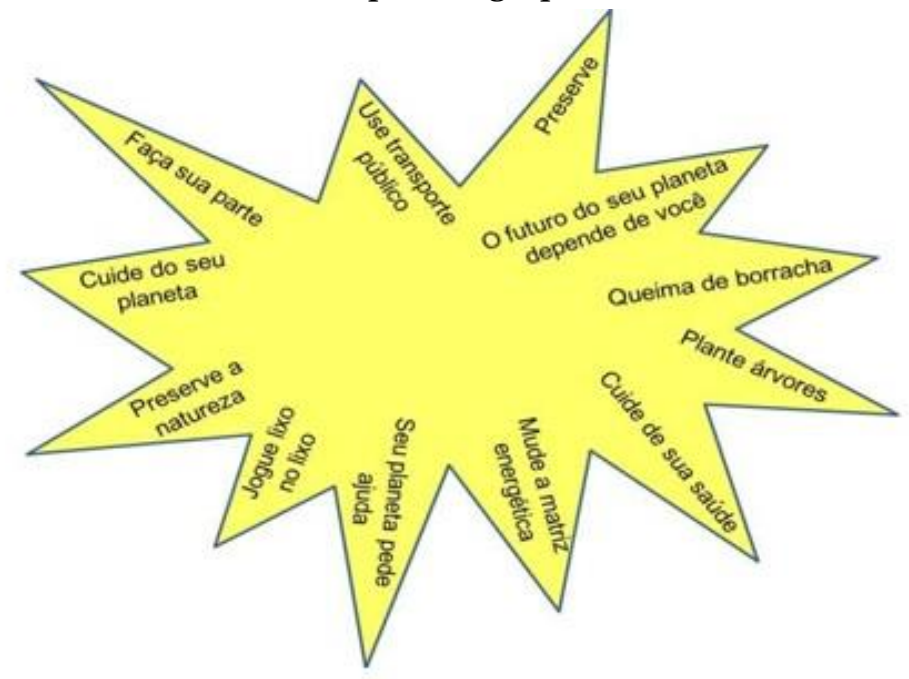

Fonte: Os autores

Para complementar e aprofundar, outra estratégia que pode ser utilizada é intitulada como "árvore de problemas” (HELMING, GÖBEL, 1998). "A árvore de problemas é uma estratégia que visa à análise de problemas, por meio da identificação das causas e efeitos relativos a um, problema central" (CAMARGO; DAROS, 2018, p.35). Para isso, os alunos permanecerão em grupos. Através da atividade anterior, os alunos tiveram contato e a oportunidade de conhecer e aprofundar sobre o tema, nessa atividade eles irão identificar as suas causas e consequências. Para isso, os alunos construirão uma árvore, uma representação gráfica, onde o tronco seria o proble- 
ma, as causas seriam as raízes e as consequências seriam os galhos e flores, como demonstra a figura 4. Para a construção da árvore de problemas, a sugestão é que os alunos desenhem a árvore em folhas de flip-chart ou folhas tamanho A3 e utilize post-its para a identificação das causas e consequências. Com essa atividade, se pretende que o aluno compreenda o problema poluição e identifique suas causas e efeitos. Após a construção da árvore, o professor pode promover uma discussão ou debate em sala de aula.

Figura 4: Representação da árvore de problema.

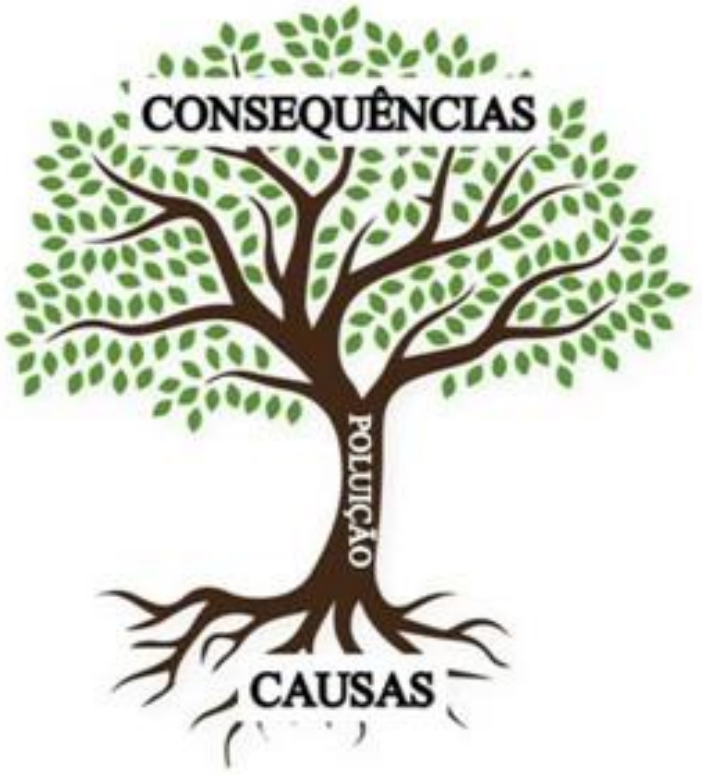

Fonte: Os autores 
Para as duas atividades pode-se perceber a participação ativa dos alunos, tanto na busca por reportagens, quanto nas discussões que resultaram na construção do mural e da árvore. Outro ponto importante a ser ressaltado é o aspecto social e político presente nessas atividades, pois contribui para que o aluno compreenda uma problemática que está presente em sua realidade através da interpretação, discussão e reflexão das reportagens sobre o tema poluição. As competências e habilidades adquiridas através dessas atividades possibilitam ao aluno a criticidade que devemos ter frente ao que é divulgado pela mídia, e com um olhar mais amplo, sobre as diversas informações que estão disponíveis na era digital na qual estamos.

Na etapa três, a sugestão é apresentar de forma expositiva e dialogada os conteúdos: química da poluição; compostos inorgânicos - ácidos, bases, sais e óxidos; saúde e poluição; poluição x desenvolvimento econômico. Ressalta-se que é disponibilizado um texto como aprofundamento químico teórico dessas temáticas e, além disso, os slides também são disponibilizados. Os recursos didáticos necessários são data show e computador, mas caso a escola não disponha desses recursos, o professor pode utilizar somente o quadro-negro.

No final da aula, o professor pode solicitar aos alunos que reflitam em casa sobre a figura 5 sugerida e respondam alguns questionamentos. A atividade sugerida 
é para ser realizada em casa, e colabora para que a reflexão sobre a temática permaneça com o aluno até a próxima aula, ampliando e intensificando a aprendizagem da temática poluição atmosférica. Além disso, as atividades são dissertativas, dando ao aluno a possibilidade de expressar suas ideias e opiniões, bem como o professor, através de uma avaliação mediadora, pode utilizar esses dados para mediar e interferir de forma mais eficaz.

Figura 5: Poluição atmosférica afeta 300 milhões de crianças no mundo.

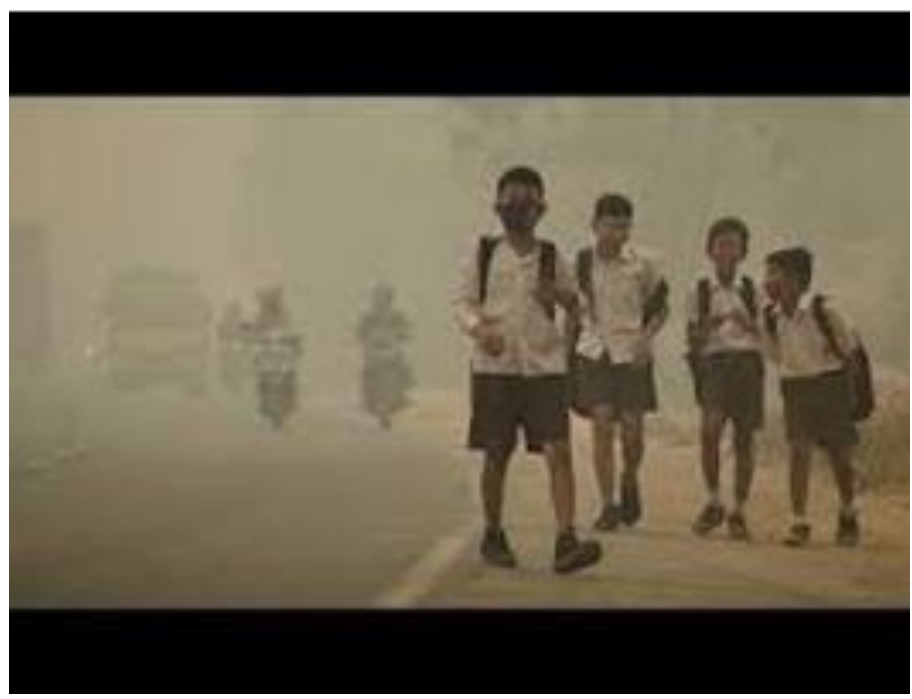

Fonte: Site EURONEWS, $2016^{3}$

3<https://pt.euronews.com/2016/10/31/poluicao-atmosferica-afeta300-milhes-de-criancas-no-mundo $>$. 
A etapa de número quatro tem como objetivo sintetizar e organizar as ideias e conceitos através da estratégia "Mapa conceitual”. O material necessário são folhas tamanho A4. Essa atividade consiste na construção de um esquema visual, que possibilita representar as relações entre conceitos, bem como suas causas, consequências e as relações que existem entre elas (MOREIRA, 1998).

Com o intuito de instruir os alunos sobre a construção de um mapa conceitual, o professor pode trazer exemplos ou até mesmo elaborar em conjunto com os alunos um mapa conceitual de outro assunto da química. Logo após, a sugestão é dividir a turma em grupos e disponibilizar os slides trabalhados na aula anterior. Os slides podem ser substituídos por algum texto ou artigo sobre o assunto trabalhado. Dividir os slides, texto ou artigo entre os grupos e solicitar que cada grupo retire os conceitos, ideias e exemplos que julgar importantes, e escrevam em uma folha de ofício. Logo após, cada grupo irá ao quadro na frente da sala e colocará seus conceitos, não se esquecendo de colocar as palavras de ligações entre um conceito e outro. Ao irem ao quadro, os grupos devem relacionar os conceitos retirados na sua parte, com os conceitos já esquematizados dos outros grupos. Importante ressaltar que cada grupo pode reorganizar o mapa, se isso for necessário, fazendo novas ligações e relações. Cada grupo, no final de sua participação, deve ler e explicar as relações feitas no mapa conceitual, externalizando os significados atribuídos (MOREIRA, 1998). Nesse mo- 
mento, o professor deve incentivar os alunos a discutirem suas ideias e as ligações feitas, atentar-se nas dificuldades e erros dos alunos, e também orientar e ser um mediador, proporcionando um ambiente de argumentação e de defesa de ideias. Assim, os alunos construirão seus próprios conhecimentos, e, além disso, adquirirão uma fundamental habilidade para a vida em sociedade, e se posicionarão criticamente diante de uma situação, respeitando e ouvindo uma opinião diferente ou até mesmo contrária.

O mapa conceitual será construído de forma coletiva no quadro da sala, sendo que os conceitos, ideias e exemplos são colocados em uma folha tamanho A4 e as setas e palavras de ligação podem ser feitas com pincel marcador ou giz, dependendo do tipo de quadro. Posteriormente, sugere-se que os alunos construam um texto dissertativo sintetizando as ideias colocadas no mapa conceitual. Isso auxiliará o aluno a organizar seus novos conhecimentos.

Para a aula cinco, inicialmente, apresentar de forma expositiva e dialogada o assunto "Chuva Ácida". Através dessa temática, o professor pode retomar e relacionar diversos conteúdos químicos, como por exemplo, reações químicas, explicando o que são produtos e reagentes e mostrando as reações químicas envolvidas na formação da chuva ácida. Com o objetivo de intensificar a aprendizagem dos alunos, a sugestão é que o professor utilize o Laboratório Didático Virtual -LabVirt. Essa fer- 
ramenta é uma iniciativa criada pela Universidade de São Paulo - USP, e nela se encontram links para simulações de assuntos da química. Ressalta-se que para acessar a simulação online, em alguns casos, é necessário habilitar o plugin do navegador (ou um software de terceiro que reproduza arquivos no formato swf), outra opção, é baixar a simulação no computador, dessa forma, o acesso pode ser feito offline (as orientações para baixar a simulação se encontram no site do LabVirt). Para essa aula, pode-se utilizar a simulação sobre os efeitos da poluição, as substâncias presentes e sua relação com a chuva ácida. A figura 6 traz uma demonstração da simulação sugerida.

Figura 6: Simulação sobre chuva ácida.

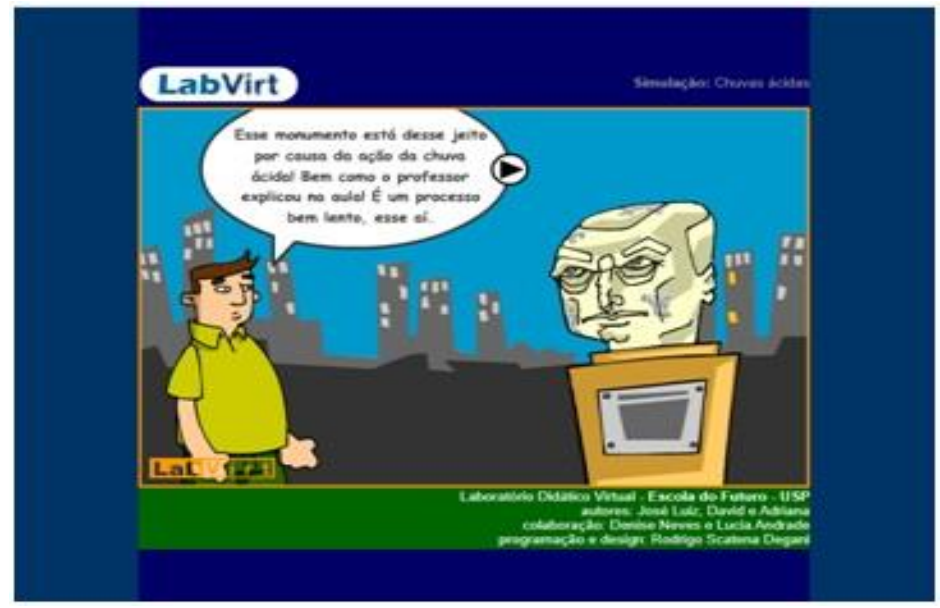

Fonte: Site Laboratório Didático Virtual - LabVirt4

\footnotetext{
${ }^{4}<$ http://www.labvirtq.fe.usp.br/simulacoes/quimica/sim_qui_chuvasacidas. htm>. Acessada em: 24/12/2020.
} 
A simulação é interativa, isso faz com que o aluno participe e teste seus conhecimentos sobre o assunto discutido em aula. Depois da utilização do recurso, o professor poderá retornar à sala de aula para discutir a proposta feita na simulação do LabVirt sobre a relação entre poluição e desenvolvimento econômico. Para contribuir, poderá solicitar a leitura da reportagem "Como combinar desenvolvimento econômico e preservação ambiental?”

A discussão através da leitura da reportagem possibilita ao aluno uma Educação Ambiental crítica, que não foca somente em como cuidar do meio ambiente e na importância de atitudes individuais ecologicamente corretas. Mas discutir a relação entre o desenvolvimento econômico e a preservação ambiental promove um entendimento amplo da realidade e que os problemas ambientais que estão presentes na atualidade estão associados muito mais à forma como a nossa sociedade está organizada, economicamente e socialmente, e com a irresponsável exploração dos recursos naturais, do que somente a atitudes individualizadas. Por isso, essa atividade de leitura e discussão dessa problemática proporciona uma visão mais ampla e integrada e menos reducionista e simplória dos problemas ambientais.

5 disponível no site https://veja.abril.com.br/ciencia/comocombinar-crescimento-economico-e-preservacao-ambiental/ 
$\mathrm{Na}$ etapa seis, a sugestão é a realização de uma visita em alguma indústria ou empresa que se localize nas proximidades da escola, com o objetivo de entender melhor os processos de produção e como a empresa lida com a questão ambiental, principalmente com a poluição atmosférica. As visitas técnicas são atividades que ampliam e facilitam a aprendizagem dos alunos, pois durante a visitação estes têm a oportunidade de conhecer e interagir com os colegas, docentes e funcionários da empresa, de forma mais próxima e efetiva, num ambiente diferente e dinâmico. Por isso, a importância dessa atividade, que aproxima a teoria da prática e também do mercado profissional, e ainda colabora para a iniciação científica, pois trabalha com questionamentos, verificação e observação.

O professor pode iniciar esse momento na aula anterior, solicitando que os alunos pesquisem em casa sobre a empresa que visitarão e como é o processo de produção, e também que anotem suas dúvidas e questionamentos. No dia da visitação, os alunos ainda na sala de aula, podem compartilhar os questionamentos que fizeram em casa, e o professor pode fomentar a discussão, possibilitando que os demais alunos contribuam com as colocações dos colegas. Logo após, durante a visitação o professor pode estimular os alunos a perguntarem e observarem, bem como anotar as respostas para os questionamentos levantados por eles. Após a visitação, o professor pode também proporcionar um momento de discussão sobre as experiências vivenciadas na visitação. 
A etapa sete consiste na finalização da unidade temática. A estratégia sugerida é a construção de um infográfico para a sintetização e publicação das informações sobre poluição nas mídias sociais da escola. O infográfico é uma ferramenta de representação de informações gráfico-visual, sendo mais atrativo e transmitindo a informação de forma mais rápida e eficiente. Essa ferramenta valoriza o texto escrito ao unir a linguagem visual e verbal, melhorando o entendimento da informação. Sendo assim, o infográfico pode ser utilizado no processo de ensino-aprendizagem como mais uma ferramenta que contribui para a eficiência desse processo. Nele estará o conteúdo de forma a combinar textos, imagens e gráficos, tornando a compreensão desse conceito mais dinâmica e desenvolvendo habilidades como interpretação.

Com isso, para iniciar a aula, o professor poderá explicar para os alunos o que são infográficos e mostrar exemplos. Importante mostrar também que essa ferramenta tem sido muito utilizada em jornais, revistas e folders com o objetivo de divulgar uma notícia de forma atrativa e rápida. Logo após essa explanação, a sugestão é que o professor leve os alunos até o laboratório de informática e solicite que selecionem as informações sobre poluição atmosférica que estarão no infográfico. Os alunos podem buscar essas informações em sites de notícias, artigos ou no material estudado nas aulas anteriores. 
Depois de selecionadas as informações, os alunos podem criar um esboço. Nele os estudantes devem organizar como as informações estarão distribuídas no infográfico. Importante ressaltar que as informações selecionadas devem ter uma ligação, não deve ser apenas um amontoado de informações sem conexão. Feito o esboço, o professor deve escolher uma ferramenta para a construção do infográfico. Há várias ferramentas disponíveis para isso, o mais usual é o PowerPoint ou o programa online Canva. Outra opção é fazer manualmente em forma de cartaz e posteriormente expor na escola. A opção escolhida nessa unidade temática é a utilização da ferramenta Canva para a construção do infográfico e divulgação posterior no Facebook na escola.

A última etapa, etapa oito, é o fechamento e a apresentação dos infográficos produzidos na aula anterior. Com isso, cada grupo pode preparar uma apresentação, mostrando as informações presentes no infográfico. Após esse momento, o professor pode aplicar um questionário com o objetivo de verificar as aprendizagens construídas pelos alunos durante a aplicação da unidade temática. Para finalizar a unidade temática, é exposta ao professor uma visão de avaliação mediadora, a qual é proposta para o diagnóstico do desempenho dos alunos. Nessa forma de enxergar o processo avaliativo, o professor precisa olhar para o aluno durante todo o processo, avaliando qualitativamente, não uma avaliação somente 
do produto final, mas de toda a caminhada de aprendizagem (HOFFMAN, 2018).

\section{Conclusões}

Após a análise e discussão das atividades e da estrutura da unidade temática, podemos reafirmar que o conhecimento prévio do aluno, a sua participação ativa no processo e a contextualização estão presentes no decorrer das atividades, propiciando uma contribuição na formação para a cidadania e uma compreensão mais ampla e crítica da relação entre o homem e meio ambiente. As atividades selecionadas, baseadas em metodologias ativas, têm importante papel, já que possuem como principal característica a inserção do estudante como agente principal e responsável pela construção da sua aprendizagem, e por isso podem ser compreendidas como práticas pedagógicas motivadoras, já que demandam o engajamento dos alunos em atividades diferenciadas, tornam as aulas mais dinâmicas e envolvem o uso de habilidades diversificadas.

Nesse sentido, podemos inferir que as metodologias ativas favorecem a aprendizagem significativa, pois surgem como proposta que tem como premissa a busca da participação ativa de todos os envolvidos no processo de aprendizagem, centrados na realidade em que estão inseridos e utilizando seus conhecimentos prévios. 
Dessa forma, o produto educacional pretende apresentar ao professor um material didático em que a contextualização é o eixo norteador, que dá significado aos conteúdos químicos que são abordados. Além disso, a contextualização vista dessa forma, implica em tornar a aprendizagem significativa para o aluno, dando possibilidade para o indivíduo ancorar seus conceitos subsunçores aos novos conhecimentos.

A unidade temática construída neste trabalho tem como público-alvo professores que buscam trabalhar em suas aulas uma metodologia diferenciada, onde o aluno tem a oportunidade de desenvolver a comunicação, a autonomia e acriticidade, o que é fundamental para a formação desses indivíduos. Ao desenvolver tais habilidades, os alunos terão a capacidade de transformar as informações de cunho científico recebidas na sua trajetória estudantil em um conhecimento funcional e empírico.

Além disso, espera-se que através do desenvolvimento em sala de aula da unidade temática "Poluição: um inimigo invisível” e, principalmente, dos momentos de reflexão proporcionados durante as aulas, que o aluno, além de compreender o mundo natural em que está inserido, possa contribuir, participar e modificar a sua realidade, fundamentado nos conhecimentos construídos na escola, bem como, que o aluno seja capaz de compreender nossa responsabilidade de cuidar e de preservar o meio ambiente. 


\section{Referências}

BRASIL. Ministério da Educação. Base Nacional Comum Curricular - BNCC. Brasília: MEC/CONSED/UNDIME, 2017.

CAMARGO, F.; DAROS, T.; A sala de aula inovadora: estratégias pedagógicas para fomentar o aprendizado ativo. Porto Alegre: Penso, 2018.

COSTA, M. A.; COUTINHO, E. H. L. Metodologias ativas $e$ currículo integrado: a travessia para as práticas pedagógicas motivadoras na educação profissional técnica de nível médio. Boletim Técnico do Senac, v.45, n.3, 2019.

FREIRE, P. Pedagogia do oprimido. $17^{\mathrm{a}}$ ed. Rio de Janeiro: Paz e Terra, 1987.

HOFFMANN, J.; Avaliação mediadora: uma prática em construção da pré-escola à universidade. 34 ed. - Porto Alegre: Mediação, 2018.

MAULINI, O. Qui a eu cette idée folle, un jour d'inventer [les notes à] l'école? Petite histoire de l'évaluation chiffrée à l'usage de celles et ceux qui désirent s' en passer (et dês autres). 1996.

MORAES, L. D. de M.; CARVALHO, R. S.; NEVES, Á. J. M. O Peer Instruction como proposta de metodologia ativa no ensino de química. The Journal of Engineering and Exact Sciences, v.2, n.3, p.107-131, 2016.

MORAN, J. M. O vídeo na sala de aula. Revista Comunicação \& Educação. São Paulo, ECA - Ed. Moderna: p.27-35, jan./abr, 1995 . 
MOREIRA, M. A.; MASINI, E. S. Aprendizagem significativa: a teoria de David Ausubel. São Paulo: Ed. Moraes, 1982.

MOREIRA, M. A. Mapas conceituais e aprendizagem significativa. Cadernos do Aplicação, v.11, n.2, p.143-156, 1998.

MOREIRA, M. A.; Organizadores prévios e aprendizagem significativa. Revista Chilena de Educación Científica, v.7, n.2, p.23-30, 2008.

OLIVEIRA, P. R. S. de. A Construção Social do Conhecimento no Ensino-Aprendizagem de Química. In Atas do IV Encontro Nacional de Pesquisa em Educação em Ciências (ENPEC), Bauru, SP, 2003.

PAIVA, M. R. F. et al. Metodologias ativas de ensinoaprendizagem: revisão integrativa. Revista Sanare, v.15, n.02, p.145-153, Jun./Dez. 2016.

PEREIRA, E. A. et al. A contribuição de John Dewey para a educação. Revista Eletrônica de Educação, v.3, n.1, p.154-161, 2009.

RAUPP, D. T. et al. Currículo por competências na educação superior. 1. ed. São Bernardo do Campo: Editora Metodista, 2019. v.50, p.107.

ROSSETTI, R. R. O ensino de química através de temas geradores ambientais. O professor PDE e os desafios da escola pública paranaense, versão online, v.1, 2007.

SANTOS, A. O. et al. Dificuldades e motivações de aprendizagem em Química de alunos do ensino médio investigadas em ações do (PIBID/UFS/Química). Scientia Plena, v.9, n.7 (b), 2013 . 
SANTOS, A. G.; NETO, A. R. P.; FRAGOSO, H. C. Método das aulas dinâmicas: uma aplicação no ensino de química. Brazilian Applied Science Review, v.3, n.1, p.529-538, 2018.

SCHWAHN, M. C. A.; OIAGEN, E. R. O uso do laboratório de ensino de Química como ferramenta: investigando as concepções de licenciandos em Química sobre o Predizer, Observar, Explicar (POE). Acta Scientiae, v.10, n.2, p.151-169, 2008.

SUART, R. de C. Habilidades cognitivas manifestadas por alunos do ensino médio de química em atividades experimentais investigativas. Dissertação de Mestrado, Programa de Pós-Graduação em Ensino de Ciências. Universidade de São Paulo - USP, 2008. 